\title{
Advertising and Aggregate Consumption: A Bayesian DSGE Assessment*
}

\author{
Benedetto Molinari and Francesco Turino
}

\begin{abstract}
Aggregate data reveal that in the U.S., advertising absorbs $2 \%$ of GDP. Because the purpose of brand advertising is to foster sales, we ask whether such spending appreciably affects aggregate consumption and economic activity. This question is addressed by developing and estimating a dynamic general equilibrium model in which households' preferences for differentiated goods depend on brand advertising. Estimated results for the U.S. economy indicate that in the long-run, the presence of advertising raises aggregate consumption, investment, and hours worked, eventually fostering overall economic activity. We also find that advertising has a relevant impact on fluctuations in consumption and investment.

"... as a matter of fact, the scale of expenditures on advertising varies positively with the general level of economic activity, so that, insofar as the effect of marginal expenditures is positive, advertising itself tends to accentuate the amplitude of economic fluctuations."
\end{abstract}

Nicholas Kaldor (1950)

In 2005, firms spent 272 billion dollars on advertising their products in U.S. media, amounting to approximately 1200 dollars per person. The U.S. advertising industry accounts for $2.2 \%$ of GDP, absorbs approximately $20 \%$ of firms' budgets for new investments and uses $16 \%$ of their corporate profits. Traditionally, the rationale for firms' spending on advertising has been identified as the positive effect of advertisements on sales. Firms realize that the demand that they face is not an exogenous product of consumers' preferences; instead, it can be tilted toward their own products through advertisements. The effectiveness of advertising in enhancing demand is not only revealed by firms' willingness to spend money on it but is also supported by a large number of empirical studies. ${ }^{1}$ Building on this fact, we

*Corresponding author: Francesco Turino, Universidad de Alicante, Dpto. Fundamentos del Análisis Económico, Campus de San Vicente, 03690 Alicante, Spain. Email: fturino@ua.es.

The authors would like to thank the editor, Morten Ravn, and two anonymous referees who kindly reviewed the earlier version of this manuscript and provided valuable suggestions and comments. The authors also wish to acknowledge useful discussion with and suggestions by Jordi Galí, Alberto Bisin, Albert Marcet, David Andolfatto, Enrique Sentana, Fabio Canova, Tim Kehoe, Andrea Caggese, Pierluigi Ciocca, M. Dolores Collado Vindel, Francesco Serti, Renzo Orsi, Davide Raggi, Sonia Oreffice, Climent Quintana-Domeque, Claudio Campanale, Antonio Minniti and participants of the 9th RCEA Bayesian Workshop, 2009 SED Annual Meeting, the Macro Workshop at UPF, the XI Workshop on Dynamic Macroeconomics in Vigo, and the ASSET 2006 Conference. Albert Marcet and Ramon Marimon are gratefully acknowledged for the financial support provided to collect the data used in the paper. The database was made available by the courtesy of the staff of Johnson Graduate School of Management Library (Sage Hall, Cornell University). Molinari acknowledges financial support from the Spanish Ministry of Science and Technology (Grants SEJ1512 and ECO2013-43526-R). Turino acknowledges financial support from MINECO/FEDER (ECO2015-70540-P).

${ }^{1} \mathrm{~A}$ survey of empirical studies on the advertising-sales relationship can be found in Vakratsas and Ambler (1999) or Bagwell (2007).

This article has been accepted for publication and undergone full peer review but has not been through the copyediting, typesetting, pagination and proofreading process, which may lead to differences between this version and the Version of Record. Please cite this article as doi: 10.1111 ecoj.12514

This article is protected by copyright. All rights reserved. 
ask whether this relationship holds in the aggregate. Because the reason for advertising is to increase consumer demand, as brand advertising increases the sales of individual goods, will aggregate advertising enhance aggregate consumption? If so, will it also increase aggregate demand and production? That is, how important are the spillovers from the advertising sector to economic activity?

To address these questions, we build and estimate a dynamic stochastic general equilibrium (DSGE) model in which we explicitly account for advertising. The usage of a Bayesian DSGE methodology to assess the advertising-consumption relationship is a novel approach in the literature. We believe that this method is a reasonable choice for at least two reasons. First, advertising is not merely a matter of demand and consumption; rather, it can affect economic activity through various other channels, for instance, by increasing the substitutability among goods, thereby influencing firms' market power, or by reducing consumers' savings, thereby decreasing future demand. A general equilibrium framework can conveniently cope with all of these effects. Second, a DSGE model incorporates both steady-state equilibrium and aggregate dynamics, thus providing a unified framework to study the long- and short-run effects of advertising in the aggregate. The model developed here is a variant of the neoclassical stochastic growth model augmented with a government sector, monopolistically competitive product markets, and real rigidities in the form of habit persistence, adjustment costs and variable capital utilization. Advertising is introduced into this framework by assuming that consumers' preferences are endogenously determined, depending on the distribution of advertising expenditures across firms. In particular, brand advertising is intended to raise the marginal utility of the advertised good, and this assumption creates a positive linkage between advertising and sales. In addition, we assume that rival advertising affects firms' sales both by attracting new customers to the market (market-enhancing effect) and by stealing existing customers from competitors (demand-stealing effect). This feature captures the classical dichotomy emphasized in the industrial organization (IO) literature: a firm's advertising may exert either positive or negative spillovers on the demand faced by competitors (e.g., Roberts and Samuelson, 1988; Karray and Martn-Herrn, 2009).

The model is estimated using quarterly data for the U.S. economy over the 1976:I-2006:IV period. Because advertising is not considered among the main business cycle indicators, the database we employ includes a novel series of total advertising expenditures gathered by aggregating firms' spending on advertisements in a number of heterogeneous U.S. media. The results of the Bayesian estimation provide evidence in favour of a positive advertisingconsumption relationship, and we show that this finding is crucially related to the degree of advertising competitiveness at the firm level. In the long run, in addition to a $6.79 \%$ increase in consumption, we find that advertising increases hours worked by $11 \%$, GDP by $6.43 \%$, and investment by $4.28 \%$. The underlying mechanism operates through a work and spend channel: because of advertising, people work more to consume more, and the perceived need for additional consumption results from the advertising signals to which people are exposed. We show that this mechanism makes households unambiguously worse off because the overworking effect more than compensates for the expansion in consumption. Furthermore, we find that the average markup increases by $1.87 \%$, thereby providing evidence in favour of an anti-competitive effect of advertising in the U.S. economy. In the short run, the spillover effects of advertising are concentrated on consumption and investment. In

This article is protected by copyright. All rights reserved. 
particular, we find that the volatility of consumption increases by $22.5 \%$, whereas that of investment declines by $13.4 \%$. These results are driven by a short-run intertemporal mechanism that pushes households to increase current consumption at the expense of savings. The resulting crowding effect on investment dampens the impact of advertising on output and, in general, softens the quantitative implications of the work and spending mechanism for short-run fluctuations.

The existing literature on the effects of advertising in the aggregate economy is largely empirical. Taylor and Weiserbs (1972), Ashley et al. (1980), Chowdhury (1994), and Jung and Seldon (1995) estimate reduced-form specifications using aggregate time series to test for the existence of an advertising-consumption relationship based on Granger causality. Although their results are controversial and not conclusive, some evidence has emerged in favour of bi-directional Granger causality between advertising and aggregate consumption in the U.S. economy. In this paper, we depart from this literature because we analyse the advertising-consumption relationship using a structural econometric approach. This methodology has the advantage of overcoming the potential problem of endogeneity affecting the reduced-form estimations cited above and additionally allows for a general assessment of the aggregate spillovers of advertising. Few other papers examine the macroeconomics of advertising from a theoretical perspective. Bisin and Benhabib (2010) analyse the conditions under which the neoclassical theory reproduces the so-called post-modernist critique of society. Grossmann (2008) analyses the welfare implications of the complementarity between advertising and R\&D expenditures in a quality-ladder model of endogenous growth. Both papers exploit a general equilibrium setup incorporating persuasive advertising $\grave{a} l a$ Dixit-Norman akin to that used in our paper. Finally, Hall (2008) analyses the general equilibrium implications of rent-seeking activities, showing that advertising is a procyclical activity.

The remainder of this paper is structured as follows. Section 1 presents the novel data on aggregate advertising used in the estimation, together with their business cycle properties. Section 2 provides the DSGE model with advertising, which is then estimated in Section 3. Section 4 analyses some properties of the estimated model, while Section 5 quantifies the short- and long-run spillovers of advertising in the U.S. economy and evaluates their welfare implications. Section 6 concludes the paper. Technical details on the estimated model and additional results are available in the online appendix.

\section{Advertising Industry in the U.S.}

In what follows, we define aggregate advertising as the total amount of spending by domestic and foreign firms to advertise their products in domestic media. In Figure 1, we assess the magnitude of aggregate advertising in the U.S. economy using the annual series of aggregate advertising constructed by Robert J. Coen of Universal McCann. Advertising experts consider this to be the most reliable and complete source of data on aggregate advertising. Panel 1 depicts real per capita advertising, which serves as a proxy for the number of advertising messages received by each individual. The statistic shows an average annual growth rate of $2 \%$, thus indicating that the intensity of advertising per consumer has grown steadily over time. Panel 2 portrays the ratio of aggregate advertising to private domestic

This article is protected by copyright. All rights reserved. 
Figure 1: Aggregate Advertising in the U.S.
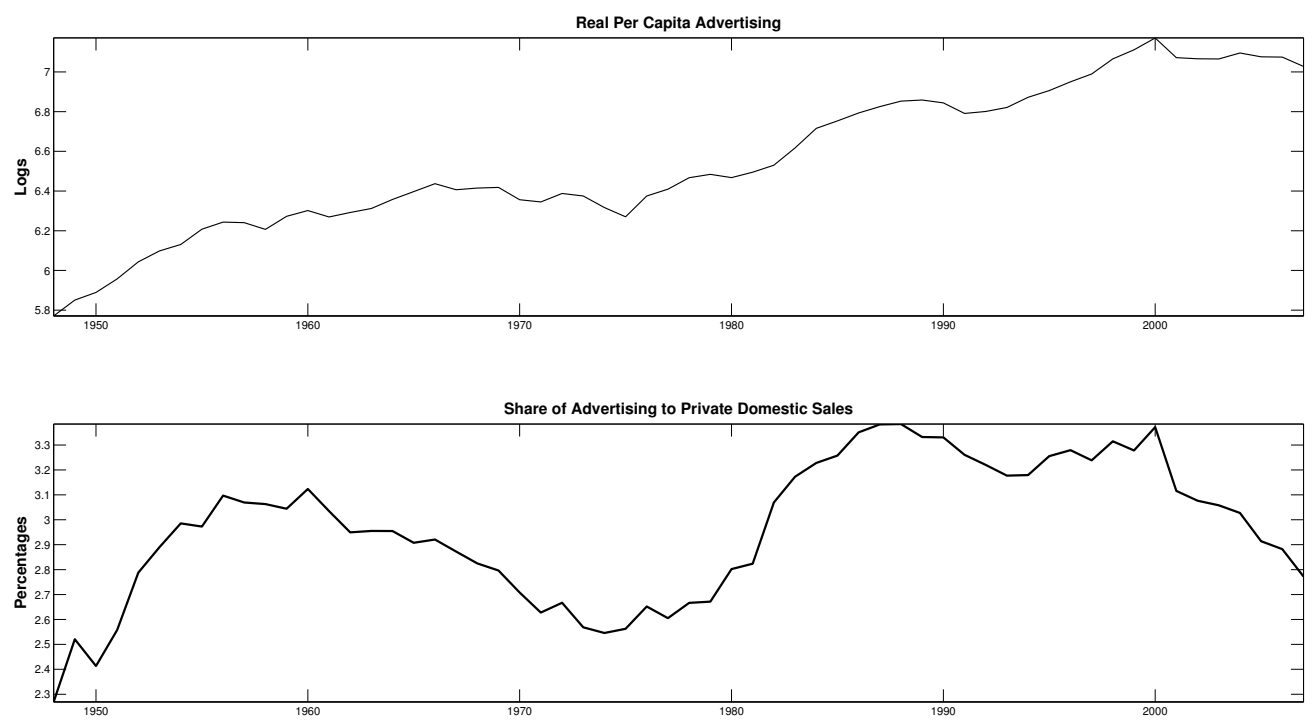

sales, which measures the fraction of resources that firms employ in marketing practice. Advertising fluctuates around a long-run mean of 3\%, accounting for, approximately, $20 \%$ of investment budgets and absorbing almost the same amount of resources as that employed in $R \& D$.

What remains unclear from previous analysis is the relationship between advertising and economic activity in the short run. Although the ratio of advertising to private domestic sales shows large fluctuations and appears positively correlated with GDP, annual data are not an ideal candidate to assess short-run comovements because they mask information on in-year contractions and expansions. To overcome this issue, we perform a proper business cycle analysis using quarterly data. Because aggregate advertising is not available among the standard business cycle indicators, we construct a novel quarterly series reporting the unweighed sum of nominal quarterly expenditures on advertisements in 10 U.S. media outlets covering the 1976-2006 period. To obtain a real series, nominal data are deflated using the GDP deflator, which has the closest resemblance to an advertising-spending-specific deflator (see Seldom and Jung, 1995). Further analysis and details on data construction and sources are given in the online appendix.

In Figure 2, we plot the cyclical component of real advertising expenditures along with real GDP (panel 1), real total consumption and real fixed private investment (panel 2). Advertising appears procyclical, more volatile than GDP and consumption, and less volatile than investment. Table 1 reports the related business cycle statistics, which confirm these findings. Advertising displays a positive correlation with GDP (0.71) and is more than twice as volatile as GDP. Furthermore, it is persistent over the cycle, with a point estimate of the first-order autocorrelation of 0.89. Concerning the other macroeconomic aggregates, advertising displays the strongest correlation with total consumption (0.66). Moreover,

This article is protected by copyright. All rights reserved. 
Figure 2: Cyclical Properties of Advertising
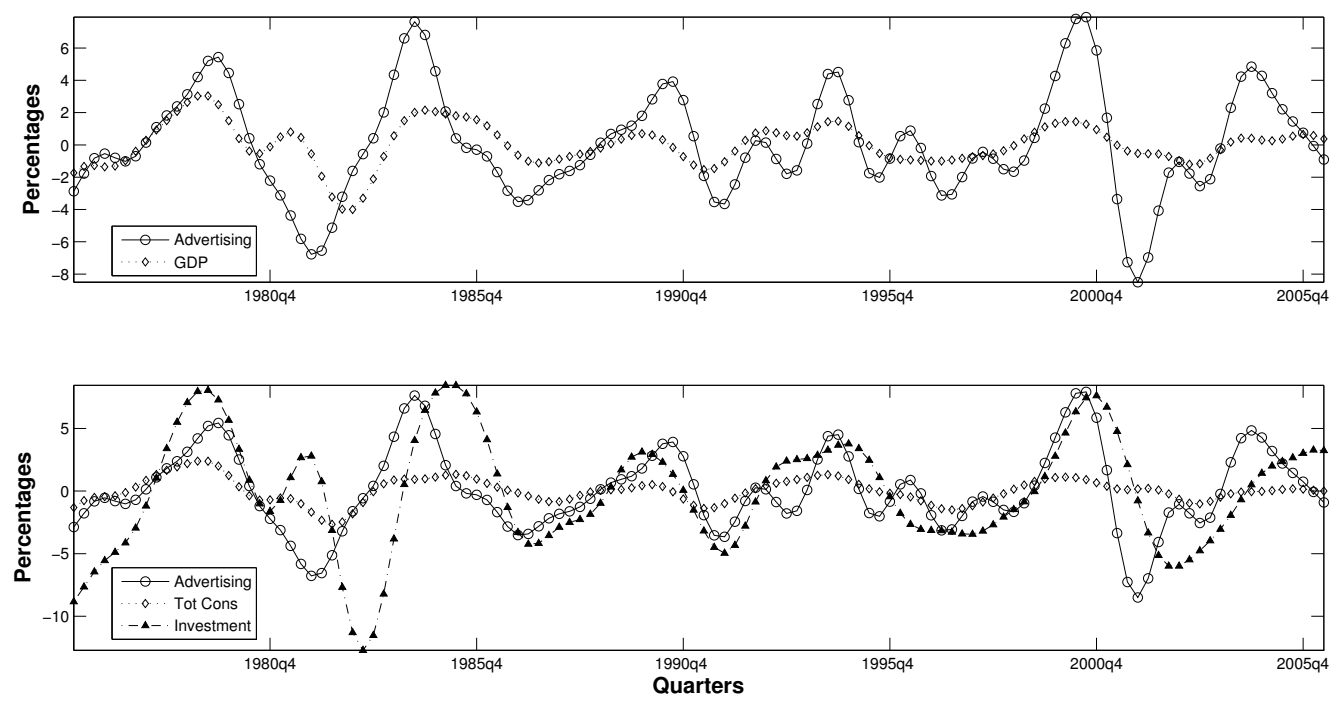

it is more than 3 times more volatile than hours worked and total consumption, almost 4 times more volatile than non-durable consumption, slightly more volatile than durable consumption and 30\% less volatile than investment. We also find that the ratio of advertising to GDP is positively correlated with GDP itself. This result suggests that firms do not spend a constant proportion of their revenues on advertising, as would be predicted by the standard theory of optimal advertising budgeting (e.g., Dorfman and Steiner, 1954).

\section{A DSGE Model with Advertising}

We consider an economy in which a continuum of differentiated goods indexed by $i \in$ $[0,1]$ are produced by monopolistically competitive producers. Goods are sold by firms to households for consumption and investment purposes and to the government, which collects taxes from households to finance public expenditures. Households' preferences for differentiated goods are not exogenous but depend on the distribution of advertising expenditures across firms. Firms are aware of this linkage and compete in the market jointly using advertising budgeting and pricing policy. All of the interactions among firms, households and the government occur in a stochastic environment in which short-run dynamics are driven by several demand and supply shocks.

\subsection{The Representative Household and the Role of Advertising}

The representative household has preferences in period 0 given by

$$
E_{0} \sum_{t=0}^{\infty} \beta^{t}\left\{\frac{\left[\left(X_{t}-\zeta X_{t-1}\right) / \Gamma_{t}\right]^{(1-\sigma)}-1}{1-\sigma}-\xi_{t}^{h} \frac{H_{t}^{1+\phi}}{1+\phi}\right\},
$$

This article is protected by copyright. All rights reserved. 
Table 1: Real Business Cycle Statistics

\begin{tabular}{l|cccc}
\hline \hline$X_{t}$ & $\frac{\sigma\left(X_{t}\right)}{\sigma\left(G d p_{t}\right)}$ & $\operatorname{corr}\left(X_{t}, A d v_{t}\right)$ & $\operatorname{corr}\left(X_{t}, G D P_{t}\right)$ & $\operatorname{corr}\left(X_{t}, X_{t-1}\right)$ \\
\hline \hline Advertising & 2.30 & 1 & 0.71 & 0.89 \\
GDP & 1 & 0.71 & 1 & 0.93 \\
Consumption & 0.63 & 0.66 & 0.91 & 0.94 \\
Non-Dur. & 0.54 & 0.62 & 0.80 & 0.93 \\
$\quad$ Durables & 2.06 & 0.62 & 0.88 & 0.93 \\
Investment & 3.00 & 0.58 & 0.83 & 0.93 \\
Hours worked & 0.66 & 0.61 & 0.90 & 0.92 \\
Adv/GDP & 1.74 & 0.91 & 0.36 & 0.87 \\
\hline \hline
\end{tabular}

Notes. Cyclical components have been extracted from data by using the Band Pass filter with (6-32) bands. The series of aggregate advertising has been pre-treated for seasonality using the X11 filter. The series of GDP is GDP minus net exports. See Appendix A for a description of data and sources.

where $X_{t}$ is the utility aggregate, $H_{t}$ is hours worked, $\beta \in(0,1)$ represents the subjective discount factor, $\zeta \in[0,1]$ controls for the degree of internal habit persistence, and $\{\phi, \sigma\} \in R_{+}^{2}$ are preference parameters. $\xi_{t}^{h}$ is a preference shock that follows a univariate autoregressive process of the form $\log \left(\xi_{t}^{h} / \xi\right)=\rho_{h} \log \left(\xi_{t-1}^{h} / \xi\right)+\epsilon_{t}^{h}$, in which $\epsilon_{t}^{h}$ are i.i.d. innovations with mean 0 and standard deviation $\sigma_{h}$. To ensure that the economy evolves along a balanced growth path, we assume that households derive utility from the object $X_{t}-\zeta X_{t-1}$ relative to the deterministic level of labour-augmenting technological progress, $\Gamma_{t}$, which grows at the constant rate $\tau>0$.

Building on Dixit and Norman (1978), we assume that the utility aggregate, $X_{t}$, takes the following form

$$
X_{t}=\left(\int_{0}^{1}\left(c_{i, t}-B\left(f_{i, t}, f_{-i, t}, \Gamma_{t}\right)\right)^{\frac{\varepsilon-1}{\varepsilon}} d i\right)^{\frac{\varepsilon}{\varepsilon-1}},
$$

where $c_{i, t}$ denotes the quantity of good $i$ consumed in period $t, \varepsilon>1$ is the pseudo-elasticity of substitution across varieties, $f_{i, t}$ and $f_{-i, t}$ denote firm's own and its competitors' goodwill, respectively, which summarize the effects of advertising outlays on preferences. Following Nerlove and Arrow (1962), we assume that the intangible stock of goodwill evolves according to the rule $f_{i, t}=\left(1-\delta_{f}\right) f_{i, t-1}+\left(1-\phi_{z}\left(z_{i, t} / z_{i, t-1}\right)\right) z_{i, t}$, where $z_{i, t}$ is a firm's investment in new advertising, $\delta_{f} \in(0,1)$ is the goodwill depreciation rate, and $\phi_{z}(\cdot)$ denotes standard quadratic adjustment costs satisfying $\phi_{z}^{\prime \prime}(\tau)=\psi_{z}>0$. Finally, function $B(\cdot)$ is specified as

$$
B(\cdot)=\frac{\theta f_{i, t}}{1+\theta f_{i, t} / \Gamma_{t}}-\gamma \frac{\theta f_{-i, t}}{1+\theta f_{-i, t} / \Gamma_{t}}
$$

where $f_{-i, t}=\int_{0}^{1} f_{j, t} d j$, parameter $\theta>0$ controls for the intensity of brand advertising in affecting consumer's preferences, and $\gamma \in[0,1]$ measures the degree of competitiveness in advertising at the firm level.

The adopted formulation implies that advertising is persuasive in that it affects consumers' choices by modifying their tastes (see Bagwell, 2007, ch.2). In the model, the

This article is protected by copyright. All rights reserved. 
persuasive effect is replicated by assuming that exposure to brand advertising creates a negative externality that induces households to feel dissatisfaction with their current levels of consumption. The utility aggregate (2) also implies that brand advertising decreases the substitutability between advertised goods and rival products (brand equity effect). ${ }^{2}$ The specification of $B(\cdot)$ in turn nests any intermediate type of advertising between two extreme cases in which advertising either merely redistributes market shares across firms or enhances the market size. The mapping is controlled by $\gamma$. Its role is apparent if one examines the demand function for good $i$, which is determined by minimizing consumption expenditures subject to the utility aggregate (2), i.e.,

$$
c_{i, t}=\left(p_{i, t} / P_{t}\right)^{-\varepsilon} X_{t}+B\left(f_{i, t}, f_{-i, t}, \Gamma_{t}\right),
$$

where $P_{t}=\left[\int_{0}^{1} p_{i, t}^{1-\varepsilon} d i\right]^{1 /(1-\varepsilon)}$ is the price index. Accordingly, an incremental investment in advertisements for rival products, $f_{-i, t}$, negatively affects the demand for good $i$. When $\gamma=$ 1 , this demand-stealing effect is maximized, and in the symmetric equilibrium, advertising is a zero-sum game that leaves the demand function unaffected. We therefore refer to this case as purely competitive advertising. Conversely, when $\gamma=0$, the demand-stealing mechanism is switched off $\left(\partial B(\cdot) / \partial f_{-i, t}=0\right)$, and brand advertising expands a producer's sales regardless of the intensity of competitors' advertising. In this case, the advertising of each individual firm exerts upward pressure on aggregate demand, eventually enhancing the market size. Finally, when $\gamma \in(0,1)$, the parametrization yields a combination of the two extreme cases in which firms' advertising both steals customers from competitors and expands the size of the market. We refer to this general case as market-enhancing advertising.

For the rest of the demand side of the model, we assume that each household holds one asset, the capital stock $\bar{K}_{t}$, and in each period $t$ chooses the capital utilization rate, $u_{t}$, to transform physical capital into effective capital according to the rule $K_{t}=u_{t} \bar{K}_{t}$. The cost of capital utilization is defined in units of physical capital and is given by $a\left(u_{t}\right)=$ $R_{s s}^{k}\left(\omega u_{t}^{2} / 2+(1-\omega) u_{t}+\omega / 2-1\right)$, where $R_{s s}^{k}$ denotes the rental rate of capital evaluated in the steady state and $\omega>0$. Physical capital evolves according to the law of motion $\bar{K}_{t+1}=$ $\left(1-\delta_{k}\right) \bar{K}_{t}+\xi_{t}^{k}\left(1-\phi_{k}\left(I_{t} / I_{t-1}\right)\right) I_{t}$, where $I_{t}$ is investment in new capital, $\delta_{k} \in(0,1)$ is the capital depreciation rate, and $\phi^{k}(\cdot)$ denotes standard quadratic adjustment costs satisfying $\phi_{k}^{\prime \prime}(\tau)=\psi_{k}>0 . \xi_{t}^{k}$ is an investment-specific shock that follows a univariate autoregressive process of the form $\log \left(\xi_{t}^{k}\right)=\rho_{k} \log \left(\xi_{t-1}^{k}\right)+\epsilon_{t}^{k}$, in which $\epsilon_{t}^{k}$ are i.i.d. innovations with mean 0 and standard deviation $\sigma_{k}$. Investment in new capital is assumed to be a composite good produced by aggregating differentiated goods via technology $I_{t}=\left(\int_{0}^{1} i_{i, t}^{(\varepsilon-1) / \varepsilon} d i\right)^{\varepsilon /(\varepsilon-1)}$.

Each household supplies labour services per unit of time and rents physical capital to firms. Labour and capital markets are perfectly competitive, with a wage rate $W_{t}$ paid per unit of labour services and a rental rate $R_{t}^{k}$ paid per unit of capital. In addition, households receive profit $\Pi_{t}$ for the ownership of firms and pay lump-sum taxes $T_{t}$ to finance exogenous and stochastic government spending $G_{t}$. In each period, the government allocates the spending $G_{t}$ over a basket of intermediate goods to maximize the amount of the composite good produced with the CES technology, $G_{t}=\left(\int_{0}^{1} g_{i, t}^{(\varepsilon-1) / \varepsilon}\right)^{\varepsilon /(\varepsilon-1)}$.

\footnotetext{
${ }^{2}$ As documented in several empirical studies, building brand equity thorough advertising is a successful strategy to differentiate firms' own products from rival brands (see e.g., Kamakura and Russell, 1993).
}

This article is protected by copyright. All rights reserved. 


\subsection{Firms}

Firms produce output by combining labour $\left(h p_{i, t}\right)$ and capital $\left(k_{i, t}\right)$ using the technology $y_{i, t}=A_{t}^{y} k_{i, t}^{1-\alpha}\left(\Gamma_{t} h p_{i, t}\right)^{\alpha}$, where $\alpha \in(0,1)$ and $A_{t}^{y}$ is a purely transitory technology shock that evolves according to $\log \left(A_{t}^{y}\right)=\rho_{y} \log \left(A_{t-1}^{y}\right)+\epsilon_{t}^{y}$, in which $\epsilon_{t}^{y}$ are i.i.d. innovations with mean 0 and standard deviation $\sigma_{y}$. Firms promote their products by incurring advertising expenditures. Advertisements are produced in-house using the technology $z_{i, t}=A_{t}^{z} \Gamma_{t} h a_{i, t}^{\alpha_{z}}$, where $\alpha_{z} \in(0,1)$ and $h a_{i, t}$ denotes advertising-related labour. $A_{t}^{z}$ measures advertisingspecific productivity and evolves according to $\log \left(A_{t}^{z}\right)=\rho_{z} \log \left(A_{t-1}^{z}\right)+\epsilon_{t}^{z}+\rho_{z y} \epsilon_{t}^{y}$, in which $\epsilon_{t}^{z}$ are i.i.d. innovations with mean 0 and standard deviation $\sigma_{z}$. The dependence of advertisingspecific shocks on innovations, $\epsilon_{t}^{y}$, is intended to capture the movements in advertising spending driven by changes in the overall productivity of the economy. We therefore refer to $A_{t}^{y}$ as an economy-wide productivity shock.

Firms jointly determine pricing policy, production plans and advertising budgeting by maximizing the discounted flow of future profits. We show in the online appendix that an optimal planning satisfies two main conditions. First, firms set the optimal price by charging a positive markup over the marginal cost, i.e.,

$$
p_{i, t}=\eta_{y, p}(i) /\left[\left(\eta_{y, p}(i)-1\right)\right] \varphi_{t} \equiv \mu_{i, t} \varphi_{t}
$$

where $\eta_{y, p}(i)=\varepsilon\left(1-B(\cdot) / y_{i, t}\right)$ denotes the price elasticity of demand, $\varphi_{t}$ is the marginal cost of production and $\mu_{i, t}$ is the optimal markup, which is increasing in $f_{i, t}$ as a result of the brand equity effect. Second, firms budget for advertising until the marginal benefit from an additional unit of advertising equals its marginal cost, as stated in the following Euler equation:

$$
\left(p_{i, t}-\varphi_{t}\right) \partial B(\cdot) / \partial f_{i, t}+\left(1-\delta_{f}\right) E_{t}\left\{\nu_{i, t+1} Q_{t, t+1}\right\}=\nu_{i, t},
$$

where $Q_{t, t+1}$ is the stochastic discount factor and $\nu_{i, t}$ is the marginal cost of producing advertising. Consistent with the dynamic nature of goodwill, the marginal benefit on the left-hand side of equation (5) is the one-period-ahead expected payoff from a marginal unit of advertising, which sums up the marginal increase in current revenues with the discounted future gain of not producing tomorrow the surviving goodwill produced today.

\section{Parameter Estimates}

\subsection{Model Estimation and Priors}

We restrict the analysis to detrended symmetric equilibria in which all firms set the same price, produce the same quantity of goods, and invest the same amount of resources in advertising. In addition, the price of goods is normalized to 1 such that all of the remaining prices are defined in terms of contemporaneous consumption. The equilibrium conditions are log-linearized around the steady state, and the resulting state-space solution is estimated by following a Bayesian approach, which is performed using quarterly U.S. data on real personal consumption expenditures, real GDP minus net exports, total hours worked, real private nonresidential fixed investment and the series of real aggregate advertising presented in Section 1. All data are in per capita terms and expressed as quarterly growth rates, with

This article is protected by copyright. All rights reserved. 
the exception of hours worked, which is expressed as demeaned log-levels. The sample period goes from the first quarter of 1976 to the end of 2006, the time span for which quarterly data on aggregate advertising are available.

Prior distributions are summarized in Table 2. The elasticity of labour in the production of advertising, $\alpha_{z}$, is beta distributed with a mean of 0.73 and a standard deviation of 0.02 . Conditional on the remaining parameters, this prior mean implies a steady-state ratio of advertising-related labour to total hours worked $(\mathrm{Ha} / \mathrm{H})$ of $0.8 \%$, which corresponds to the average fraction of the labour force employed in the advertising industry during the 2002-2012 period, as reported by the Bureau of Labor Statistics. The prior for $\gamma$ is a uniform $[0,1]$ distribution that reflects our neutral stance between competitive and marketenhancing advertising. The goodwill depreciation rate, $\delta_{f}$, is assumed to follow a highly disperse beta distribution with a mean of 0.15 , implying a half-life of the goodwill stock of approximately four quarters. This value is consistent with the empirical evidence provided in Leone (1995), according to which the effect of advertising on a firm's demand is short-lived. The parameter controlling for advertising adjustment costs, $\psi_{z}$, is assumed to be gamma distributed with a mean of 4 and a standard error of 1 , which implies an equivalent elasticity of the adjustment costs in the laws of motion of capital and advertising. Prior distributions for the other parameters are consistent with previous studies (Smets and Wouters, 2007; Iacoviello and Neri, 2010).

Five parameters are fixed in the estimation procedure. The gross elasticity of substitution across varieties, $\varepsilon$, and the depreciation rate of capital, $\delta_{k}$, are set to 11.27 and 0.010 , respectively, to match the long-run average markup (1.11) and investment share (20\%). The intensity of advertising in enhancing demand, $\theta$, is calibrated at 1.36 , implying a longrun ratio of advertising expenditures to GDP of 0.029 , which is consistent with the data. Following Ravn et al. (2006), the government spending-to-GDP ratio, $\bar{G} / Y$, is set to 0.12 , whereas the preference parameter, $\xi$, is chosen such that the steady-state value of hours worked is equal to 0.25 , thus implying that households devote $1 / 4$ of their time to labour activities.

\subsection{Posterior Distributions}

Jointly with their corresponding priors, Table 2 reports posterior means and the $90 \%$ probability intervals for the estimated parameters. According to the reported results, all advertising-related parameters are estimated quite accurately. The data appear particularly informative regarding the competitiveness parameter, $\gamma$, the posterior probability interval of which is approximately $50 \%$ smaller than its prior counterpart. Its posterior mean is 0.593 , and the upper bound, $\gamma=1$, lies well outside the $90 \%$ posterior probability interval, thereby indicating that a market-enhancing effect of advertising is active in the U.S. economy. The data are also substantially informative with respect to the parameter controlling for the adjustment costs of advertising, $\psi_{z}$. Its posterior mean is equal to 1.227 , suggesting a much faster response of advertising to shocks than what was assumed a priori.

Regarding the stochastic processes, we find that government shocks, labour supply shocks and economy-wide productivity shocks are quite persistent, with coefficients of autocorrelation ranging between 0.94 and 0.98. Advertising and investment-specific shocks show a milder persistence, with autocorrelation coefficients equal to 0.84 and 0.75 , respectively.

This article is protected by copyright. All rights reserved. 
Table 2: Prior and Posterior Distributions

\begin{tabular}{|c|c|c|c|c|c|c|}
\hline \multicolumn{5}{|c|}{$\underline{\text { Priors }}$} & \multicolumn{2}{|c|}{ Posteriors } \\
\hline Parameter & Density & Domain & Mean & $90 \%$ interval & Mean & $90 \%$ interval \\
\hline$\beta$ & Beta & {$[0,1)$} & 0.995 & {$\left[\begin{array}{ll}0.991 & 0.998\end{array}\right]$} & 0.993 & {$\left[\begin{array}{ll}0.989 & 0.997\end{array}\right]$} \\
\hline$\sigma$ & Gamma & $R_{+}$ & 2.000 & {$\left[\begin{array}{ll}1.255 & 2.887\end{array}\right]$} & 1.366 & {$\left[\begin{array}{ll}0.857 & 1.896\end{array}\right]$} \\
\hline$\phi$ & Gamma & $R_{+}$ & 0.770 & {$\left[\begin{array}{lll}0.167 & 1.732\end{array}\right]$} & 2.143 & {$\left[\begin{array}{ll}1.150 & 3.073\end{array}\right]$} \\
\hline$\gamma$ & Uniform & {$[0,1]$} & 0.500 & {$[0.050 \quad 0.950]$} & 0.593 & {$\left[\begin{array}{ll}0.354 & 0.822\end{array}\right]$} \\
\hline$\delta_{f}$ & Beta & {$[0,1]$} & 0.150 & {$\left[\begin{array}{lll}0.025 & 0.343\end{array}\right]$} & 0.164 & {$\left[\begin{array}{ll}0.069 & 0.279\end{array}\right]$} \\
\hline$\alpha$ & Beta & {$[0,1]$} & 0.708 & {$\left[\begin{array}{ll}0.674 & 0.740\end{array}\right]$} & 0.741 & {$\left[\begin{array}{ll}0.714 & 0.770\end{array}\right]$} \\
\hline$\alpha_{z}$ & Beta & {$[0,1]$} & 0.734 & {$[0.700 \quad 0.766]$} & 0.717 & {$\left[\begin{array}{ll}0.685 & 0.748\end{array}\right]$} \\
\hline$\tau^{*}$ & Normal & $R$ & 0.005 & {$\left[\begin{array}{ll}.0017 & .0083\end{array}\right]$} & .0045 & {$\left[\begin{array}{ll}.0040 & .0049\end{array}\right]$} \\
\hline$\psi_{k}$ & Gamma & $R_{+}$ & 4.000 & {$\left[\begin{array}{ll}2.509 & 5.774\end{array}\right]$} & 3.141 & {$\left[\begin{array}{ll}1.822 & 4.350\end{array}\right]$} \\
\hline$\psi_{z}$ & Gamma & $R_{+}$ & 4.000 & {$\left[\begin{array}{ll}2.509 & 5.774\end{array}\right]$} & 1.227 & {$\left[\begin{array}{ll}0.464 & 1.969\end{array}\right]$} \\
\hline$\psi_{u}$ & Beta & $(0,1)$ & 0.500 & {$\left[\begin{array}{ll}0.171 & 0.828\end{array}\right]$} & 0.360 & {$\left[\begin{array}{ll}0.104 & 0.602\end{array}\right]$} \\
\hline$\zeta$ & Beta & {$[0,1]$} & 0.500 & {$\left[\begin{array}{ll}0.171 & 0.828\end{array}\right]$} & 0.321 & {$\left[\begin{array}{ll}0.178 & 0.467\end{array}\right]$} \\
\hline $\bar{\rho} \rho_{y}$ & Beta & {$[0,1)$} & 0.500 & {$\left[\begin{array}{ll}0.172 & 0.828\end{array}\right]$} & 0.940 & {$\left[\begin{array}{ll}0.892 & 0.985\end{array}\right]$} \\
\hline$\rho_{h}$ & Beta & {$[0,1)$} & 0.900 & {$\left[\begin{array}{ll}0.807 & 0.967\end{array}\right]$} & 0.945 & {$\left[\begin{array}{ll}0.917 & 0.974\end{array}\right]$} \\
\hline$\rho_{g}$ & Beta & {$[0,1)$} & 0.500 & {$\left[\begin{array}{ll}0.172 & 0.828\end{array}\right]$} & 0.956 & {$\left[\begin{array}{ll}0.934 & 0.978\end{array}\right]$} \\
\hline$\rho_{k}$ & Beta & {$[0,1)$} & 0.500 & {$\left[\begin{array}{lll}0.172 & 0.828\end{array}\right]$} & 0.750 & {$\left[\begin{array}{ll}0.606 & 0.900\end{array}\right]$} \\
\hline$\rho_{z}$ & Beta & {$[0,1)$} & 0.900 & {$\left[\begin{array}{ll}0.807 & 0.967\end{array}\right]$} & 0.842 & {$\left[\begin{array}{ll}0.720 & 0.960\end{array}\right]$} \\
\hline$\rho_{z y}$ & Beta & {$[0,1]$} & 0.800 & {$\left[\begin{array}{lll}0.505 & 0.981\end{array}\right]$} & 0.804 & {$\left[\begin{array}{ll}0.593 & 0.998\end{array}\right]$} \\
\hline$\sigma_{y}$ & InvGamma & $R_{+}$ & 0.008 & {$\left[\begin{array}{ll}0.002 & 0.022\end{array}\right]$} & 0.006 & {$\left[\begin{array}{ll}0.005 & 0.007\end{array}\right]$} \\
\hline$\sigma_{h}$ & InvGamma & $R_{+}$ & 0.006 & {$\left[\begin{array}{ll}0.001 & 0.017\end{array}\right]$} & 0.022 & {$\left[\begin{array}{ll}0.014 & 0.029\end{array}\right]$} \\
\hline$\sigma_{g}$ & InvGamma & $R_{+}$ & 0.010 & {$\left[\begin{array}{ll}0.002 & 0.029\end{array}\right]$} & 0.048 & {$\left[\begin{array}{ll}0.043 & 0.053\end{array}\right]$} \\
\hline$\sigma_{k}$ & InvGamma & $R_{+}$ & 0.008 & {$\left[\begin{array}{ll}0.002 & 0.022\end{array}\right]$} & 0.025 & {$\left[\begin{array}{ll}0.015 & 0.035\end{array}\right]$} \\
\hline$\sigma_{z}$ & InvGamma & $R_{+}$ & 0.006 & {$\left[\begin{array}{ll}0.001 & 0.017\end{array}\right]$} & 0.041 & {$\left[\begin{array}{ll}0.027 & 0.056\end{array}\right]$} \\
\hline
\end{tabular}

Notes. In the estimation of the model, we adopt the normalization used in Smets and Wouters (2007) by specifying the prior distribution for the curvature parameter $\omega$ in terms of $\psi_{u}=\omega /(1+\omega)$.

This result is likely to be driven by the presence of adjustment costs, which generate endogenous persistence and therefore reduce the degree of exogenous autocorrelation needed to match the actual persistence in investment and advertising data. The estimates of the other structural parameters are consistent with the evidence available in the literature, with the exception of the habits persistence parameter, $\zeta$, which is substantially lower than existing estimates (e.g., Smets and Wouters, 2007). The smaller degree of habits is most likely due to the presence of goodwill in the marginal utility, which generates an additional mechanism that helps to match the persistence in actual consumption data.

\section{Properties of the Estimated Model}

\subsection{Impulse Responses}

To disentangle the mechanisms through which advertising affects the aggregate economy, Figure 3 depicts the estimated impulse response functions (IRF) of selected endogenous

This article is protected by copyright. All rights reserved. 
Figure 3: IRF of Selected Variables to a 1\% Increase in the Productivity of Advertising
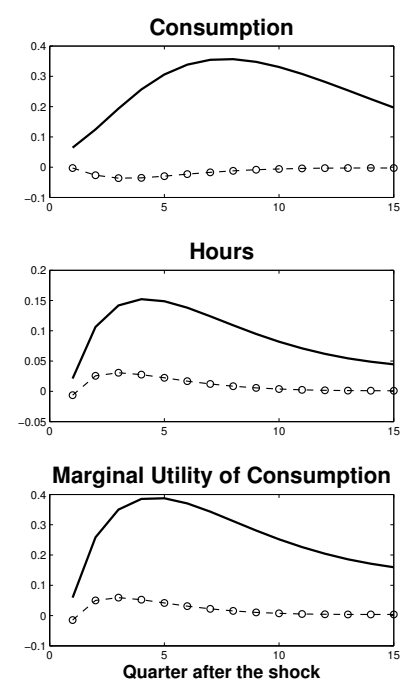

$$
\text { - }
$$

Notes. IRF with purely competitive advertising are computed by setting $\gamma=1$ while holding all the remaining parameters at their posterior mean values.

variables to a $1 \%$ increase in the advertising-specific shock $\left(\varepsilon_{t}^{z}\right)$. A transitory boost in the productivity of advertising (i) raises consumption, total hours worked, and markup; (ii) induces a decline in investment and the wage rate; and (iii) leaves production-related hours and output virtually unaffected. A positive $\varepsilon_{t}^{z}$ shock reduces the marginal cost of producing advertising and strengthens firms' incentives to expand their goodwill stocks. In turn, greater goodwill raises the marginal utility of current consumption for several quarters after the shock, thus providing a long-lasting influence on consumers' choice. ${ }^{3}$ This mechanism triggers two key effects in the model economy. On the one hand, the increase in the instantaneous marginal utility makes the household less willing to smooth consumption through savings (intertemporal effect), thus driving a persistent decline in investment accompanied by a positive and hump-shaped consumption response. Eventually, these two countervailing effects jointly determine the muted response of output. On the other hand, the same mechanism makes a household more willing to substitute consumption for leisure (intratemporal effect), thus shifting the labour supply to the right and driving the eventual increase in total hours worked and a decline in the real wage. The muted response of production-related labour reveals that the increase in total hours worked is mostly absorbed by the reallocation of labour to the advertising sector and suggests that the output dynamics are entirely determined by the intertemporal effect. Finally, the brand equity effect of advertising implies that the price elasticity of each good decreases with a larger goodwill stock, thus explaining the increase in the average markup after a positive advertising-specific shock.

Figure 3 also depicts the IRF in a counterfactual economy with purely competitive advertising. As the figure illustrates, the market-enhancing effect is the key property of the

\footnotetext{
${ }^{3}$ This effect is apparent in Figure 3, which shows that both the marginal utility of consumption and consumption itself display a positive and hump-shaped response to the shock.
}

This article is protected by copyright. All rights reserved. 
Figure 4: IRF of Selected Variables to a 1\% Increase in Economy-wide Productivity
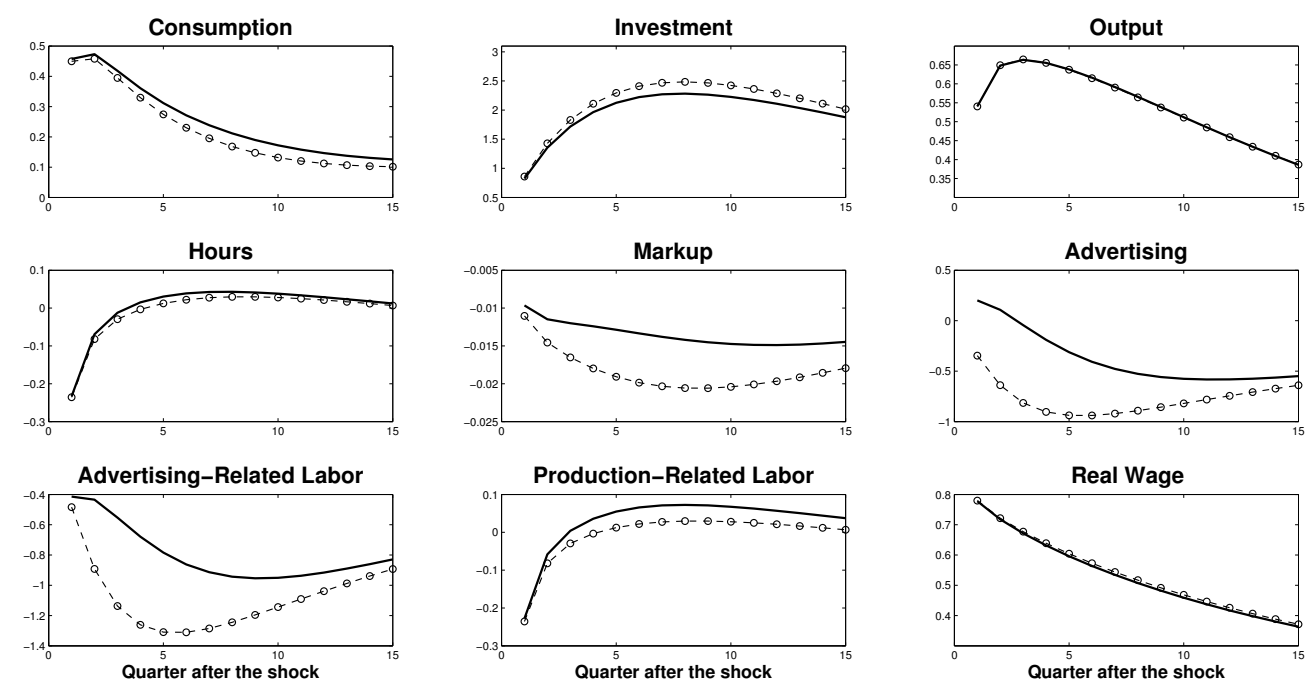

Estimated model $\left(\rho_{z y}=0.804\right) \quad$ _ $\_$- Idiosyncratic Technological Shocks $\left(\rho_{z y}=0\right)$

Notes. The counterfactual IRF are computed by setting $\rho_{z y}=0$ while holding all the remaining parameters at their posterior mean values.

estimated model for generating a positive and persistent response of consumption after an increase in aggregate advertising. Absent this effect (i.e., $\gamma=1$ ), an exogenous boost in advertising productivity raises the equilibrium level of advertising but induces a negative and short-lived consumption response. The reason is that the demand for goods, the marginal utility of consumption, and the labour supply in this case are all independent of advertising. Hence, the labour reallocation induced by the shock is the only mechanism through which advertising affects the aggregate economy. This effect shifts resources from a productive to a now unproductive sector (advertising), thereby determining the slight decline in output and its components.

Beyond the direct effects of advertising-specific shocks, the presence of advertising also induces an amplification mechanism for technology shocks. This additional channel can be isolated by comparing the estimated impulse response functions to a positive economy-wide technology shock with those implied by a counterfactual economy with idiosyncratic technological shocks (i.e., $\rho_{z y}=0$ ). As is apparent from Figure 4, the response of consumption is amplified in the estimated model. Intuitively, when $\rho_{z y}>0$, a positive technology shock also increases the productivity of advertising, thereby pushing firms to expand their goodwill stocks. The resulting greater goodwill raises the instantaneous marginal utility, thus providing the additional consumption response. The muted response of investment and the virtually identical response of total hours worked clarify that the amplification effect on consumption occurs at the expense of savings and not of leisure.

Finally, Figure 4 reveals that the countercyclical response of the average markup is substantially muted in the estimated model, which is a direct implication of the brand equity effect of advertising. In our model, the countercyclical response of the markup is driven by the time-varying price elasticity of each good $i$, which is an increasing function of

This article is protected by copyright. All rights reserved. 
aggregate demand, $\left(X_{t}+I_{t}+G_{t}\right)$, i.e.,

$$
\eta_{y, p}(i)=\varepsilon\left(1+\frac{B\left(F_{t}, F_{t}, \Gamma_{t}\right)}{\left(p_{i, t} / P_{t}\right)^{-\varepsilon}\left(X_{t}+I_{t}+G_{t}\right)}\right)^{-1} .
$$

Hence, any shock enhancing aggregate demand also pushes firms to cut markups. When the amplification mechanism is active, however, the negative effect of a larger goodwill stock on the price elasticity counteracts the impact of aggregate demand, thereby softening the countercyclical response of markups.

Although in the model the negative relationship between markups and the aggregate demand stems from the brand equity assumption, in equilibrium, this mechanism is akin to the price elasticity effect induced by external deep habits in the formulation proposed by Ravn et al. (2006). However, there is a crucial difference between the two models, which lies in how customer bases are built. With deep habits, whenever firms find it convenient to build their customer bases, they cut current markups because the future demands for individual varieties depend positively on current sales. In our model, firms build customer bases by incurring advertising expenditures, and this raises current markups, as discussed above. Hence, advertising and deep habits have the opposite implications for firms' pricing policies.

\subsection{Sources of Advertising and Consumption Comovements}

In this section, we use the estimated model to analyse the sources of comovements between advertising and aggregate consumption. To this end, some useful insights can be elicited from the optimal advertising policy (5) evaluated at the symmetric equilibrium

$$
F_{t}=\Phi_{t}\left(1-\mu_{t}^{-1}\right)\left(\eta_{c, f}(t) C_{t}\right),
$$

where $\eta_{c, f}(t)>0$ stands for the elasticity of the demand for individual varieties of goods with respect to goodwill, and $\Phi_{t}=1 /\left[\nu_{t}-\left(1-\delta_{f}\right) E_{t} \nu_{t+1} Q_{t, t+1}\right]>0$. Equation (6) states that any shock that increases aggregate consumption $\left(C_{t}=\int_{o}^{1} c_{i, t}\right)$ also pushes firms to expand their goodwill stocks. This is the direct source of the comovements between advertising and consumption and stems from firms' strategic use of advertising to maintain their market shares when market demand increases. This effect can be either amplified or attenuated by simultaneous changes in the term $\left(1-\mu_{t}^{-1}\right)$, depending on whether the shock decreases or increases the price elasticity of demand. Finally, the term $\Phi_{t}$ captures the indirect sources of correlation between consumption and advertising driven by temporary changes in technology and by movements in factor prices.

To assess the relative importance of these different sources, we simulate the model by excluding one shock at a time and then computing the implied correlation between consumption and advertising in each case. The results of this experiment are summarized in Table 3, where we also report the predicted correlation when all the shocks are active (baseline estimation) and the correlation implied by idiosyncratic technological shocks (panel B). As the table illustrates, advertising-specific $\left(\varepsilon_{t}^{z}\right)$ and economy-wide technology $\left(\varepsilon_{t}^{y}\right)$ shocks are the most important driving forces of the predicted correlation, as shutting down these

This article is protected by copyright. All rights reserved. 
Table 3: Sources of Advertising-Consumption Comovements

\begin{tabular}{l|l|ccccc|c}
\hline \hline & Baseline & \multicolumn{5}{|c}{ Counterfactual } \\
\cline { 3 - 7 } & Estimation & & $\begin{array}{c}\text { (A) Excluding shock: } \\
\text { Advertising Technology }\end{array}$ & Labour & Government & Investment & $\rho_{z y}=0$ \\
& & $\left(\varepsilon_{t}^{z}\right)$ & $\left(\varepsilon_{t}^{y}\right)$ & $\left(\varepsilon_{t}^{h}\right)$ & $\left(\varepsilon_{t}^{g}\right)$ & $\left(\varepsilon_{t}^{k}\right)$ & \\
\hline $\operatorname{Corr}\left(Z_{t}, C_{t}\right)$ & 0.61 & 0.39 & 0.29 & 0.52 & 0.65 & 0.68 & 0.34 \\
\hline \hline
\end{tabular}

Notes. Predicted correlations are computed by simulating the estimated model with the smoothed estimates of active shocks and then filtering the simulated series with the $\mathrm{BP}(6,32)$ filter. In panel $\mathrm{B}$, the correlation is computed using the estimated model with all shocks active and all parameters set at their posterior mean values, except for $\rho_{z y}$, which is set equal to 0 .

shocks reduces the statistic by approximately $40 \%$ and $60 \%$, respectively, whereas the effect of other shocks is either negligible or much smaller. In addition, panel B highlights the importance of the comovements between these two shocks in matching the advertisingconsumption correlation. The counterfactual model with $\rho_{z, y}=0$, in fact, only explains approximately half of the correlation in the data.

\section{Quantitative Results}

In what follows, we use the estimated model to quantify the aggregate implications of advertising and provide an answer to the questions posited in the introduction. We find that advertising enhances consumption both in the long (Section 5.1) and in the short run (Section 5.2), even though the overall spillovers are noticeably different depending on the time horizon considered. While in the long run advertising fuels overall economic activity, in the short run it has a contained impact on output because the positive effect driven by higher aggregate consumption is offset by a crowding-out effect on investment. The analysis is concluded by discussing the welfare implications of these findings (Section 5.3). Throughout the section, the effects of advertising are identified using a counterfactual model that is identical to the baseline estimated model except for the assumption that advertising is banned. We refer to this case as the benchmark economy without advertising.

\subsection{Long-run Spillovers}

Panel A of Table 4 reports the estimated steady state of selected endogenous variables in percentage deviations from their counterparts in the benchmark economy without advertising. According to the estimated model, advertising substantially stimulates consumption $(6.79 \%)$, GDP $(6.43 \%)$ and investment $(4.28 \%)$; induces a strong increase in hours worked $(11 \%)$; and drives a decline in the wage rate $(-2.47 \%)$. Furthermore, it moderately raises the average markup $(1.87 \%)$ and leads to a more consumption-based economy (the share of consumption in GDP increases by $0.40 \%$ ).

In the long run, the intertemporal effect of advertising is switched off because the only investment undertaken is the one that replaces the depreciated capital. The intratemporal effect of advertising is instead at work and drives the observed spillovers. This result can

This article is protected by copyright. All rights reserved. 
Table 4: Long-run Spillovers

\begin{tabular}{|c|c|c|c|c|}
\hline \multirow[t]{2}{*}{ Model } & \multicolumn{2}{|c|}{ (A) Estimated $(\gamma=0.593)$} & \multicolumn{2}{|c|}{ (B) Counterfactual $(\gamma=1)$} \\
\hline & Median & $90 \%$ interval & Median & $90 \%$ interval \\
\hline Consumption & 6.79 & {$\left[\begin{array}{ll}0.42 & 17.3\end{array}\right]$} & -1.56 & {$\left[\begin{array}{ll}-2.77 & -0.37\end{array}\right]$} \\
\hline Total hours worked & 11.0 & {$\left[\begin{array}{ll}1.58 & 25.3\end{array}\right]$} & 0.99 & {$\left[\begin{array}{ll}0.25 & 1.81\end{array}\right]$} \\
\hline Wage & -2.47 & {$\left[\begin{array}{ll}-6.28 & -0.25\end{array}\right]$} & 0 & - \\
\hline GDP & 6.43 & {$\left[\begin{array}{ll}0.47 & 16.9\end{array}\right]$} & -1.55 & {$\left[\begin{array}{ll}-2.73 & -0.33\end{array}\right]$} \\
\hline Investment & 4.28 & {$\left[\begin{array}{ll}0.05 & 12.2\end{array}\right]$} & -1.55 & {$\left[\begin{array}{ll}-2.73 & -0.33\end{array}\right]$} \\
\hline Markup & 1.87 & {$[0.19$ 4.92] } & 0 & - \\
\hline Consumption share & 0.40 & {$[0.041 .02]$} & 0 & - \\
\hline
\end{tabular}

Notes. For each variable, the effect of advertising is computed as the percentage variation of its steady state from the corresponding steady state value in the benchmark model without advertising. To account for parameter uncertainty, we construct a random section of 50,000 draws from the posterior distribution and compute the steady-state effects for each draw. Summary statistics are then computed by pooling all the simulations. For each draw, the benchmark steady state is computed from the estimated model by setting $\theta=0$. The counterfactual model in panel $\mathrm{B}$ is computed using the estimated parameters, except for $\gamma$, which is set equal to 1 .

be made explicit by observing that the households' intratemporal optimality condition in the steady-state equilibrium reads as

$$
\xi^{h} H^{\phi}(C-(1-\gamma) \theta F /(1+\theta F))^{\sigma} / \Lambda=W
$$

where $\Lambda=(1-\beta \zeta / \tau)^{1 / \phi}(1-\zeta / \tau)^{-\sigma}$. Any positive amount of advertising $(F>0)$ implies that the marginal rate of substitution between consumption and leisure is smaller than in the benchmark economy without advertising, thus resulting in more hours $(H)$ supplied in the labour market and a lower wage $(W)$ as a general equilibrium result. The abundance of cheaper labour in turn induces firms to expand their production, and the associated positive effect on income explains the observed increase in consumption and investment. Furthermore, the production of goods becomes more labour intensive and the optimal capital-output ratio declines. ${ }^{4}$ The investment share thus decreases, and this explains the associated increases in the consumption share. Additionally, because market-enhancing advertising is effective in shifting consumers' preferences, firms exploit the wedge between perceived and true product differentiation by charging higher prices. In equilibrium, the average markup increases, implying an anti-competitive effect of advertising in the U.S. economy.

The above mechanism linking advertising to consumption through the labour supply is known in the literature as the work and spend cycle and has been empirically supported by Baker and George (2010) for the U.S. and by Fraser and Paton (2003) for the U.K. Our results complement and extend this empirical evidence, showing that the effectiveness of the work and spend channel crucially depends on the degree of competitiveness in advertising. In fact, equation (7) highlights that in the purely competitive case, the marginal

\footnotetext{
${ }^{4}$ This is true because the equilibrium capital rental rate $\left(R^{k}=\left(\tau-\beta\left(1-\delta_{k}\right)\right) / \beta\right)$ is independent of advertising and common across the baseline and the benchmark economy.
}

This article is protected by copyright. All rights reserved. 
Table 5: Short-run Spillovers

\begin{tabular}{l|ccccc}
\hline \hline & \multicolumn{5}{c}{ Variables } \\
& Consumption & Hours & Investment & GDP & Markup \\
\hline (A) Asymptotic variance decomposition (percentages) \\
\hline (A.1) Baseline estimation \\
Productivity $\left(\epsilon_{t}^{y}\right)$ \\
Labuor supply $\left(\epsilon_{t}^{h}\right)$ & 32.3 & 6.17 & 19.6 & 49.1 & 4.51 \\
Government $\left(\epsilon_{t}^{g}\right)$ & 21.0 & 64.0 & 13.1 & 33.7 & 2.31 \\
Investment $\left(\epsilon_{t}^{k}\right)$ & 13.7 & 14.0 & 5.29 & 9.10 & 1.40 \\
Advertising $\left(\epsilon_{t}^{h}\right)$ & 16.1 & 11.6 & 50.0 & 7.91 & 1.77 \\
\hline
\end{tabular}

(A.2) Purely competitive advertising $(\gamma=1)$

\begin{tabular}{l|lllll} 
Productivity $\left(\epsilon_{t}^{y}\right)$ & 36.2 & 5.16 & 20.9 & 51.0 & 0 \\
Labor Supply $\left(\epsilon_{t}^{h}\right)$ & 24.6 & 71.0 & 13.9 & 34.4 & 0 \\
Government $\left(\epsilon_{t}^{g}\right)$ & 16.8 & 12.4 & 5.89 & 7.28 & 0 \\
Investment $\left(\epsilon_{t}^{k}\right)$ & 22.1 & 11.2 & 59.1 & 6.91 & 0 \\
Advertising $\left(\epsilon_{t}^{h}\right)$ & 0.21 & 0.20 & 0.18 & 0.41 & 0
\end{tabular}

(B) Historical contribution (\% change in volatility)

\begin{tabular}{l|ccccc}
\hline All Shocks & 22.5 & 15.8 & -13.4 & 12.9 & - \\
No Advertising Shock & -11.6 & 5.10 & 12.6 & 14.1 & - \\
\hline \hline
\end{tabular}

Notes. If not otherwise specified, all of the statistics reported in the table are computed by setting parameters to the posterior mean values. Asymptotic variance decomposition refers to HP(1600) filtered variables.

rate of substitution between consumption and leisure coincides with that of the benchmark economy, and therefore, the labour supply becomes independent of advertising. The work and spend mechanism is also crucial in determining both the sign and scale of the overall spillover effects of advertising. This can be seen in panel B of Table 4, where we report the steady-state effects in the counterfactual economy with purely competitive advertising. The comparison with the estimated model highlights that (i) without the labour supply effect, advertising would be wasteful in the long run, as GDP and its components all decline when $\gamma=1$, and (ii) in both cases, hours worked increase in equilibrium, but the effect of the work and spend cycle is more than 10 times larger than the labour reallocation effect induced by purely competitive advertising. In the literature, the importance of the labour supply effect was already postulated by Galbraith (1958), who argued that firms use advertising as a way to manipulate preferences with the aim of fostering high levels of consumption to increase profits. This process would affect agents' decisions regarding consumption and leisure, eventually increasing the supply of labour and the monopolistic power of firms and inducing a greater need for material consumption that makes the economy more consumption based. Our results are in line with Galbraith's conjecture.

This article is protected by copyright. All rights reserved. 

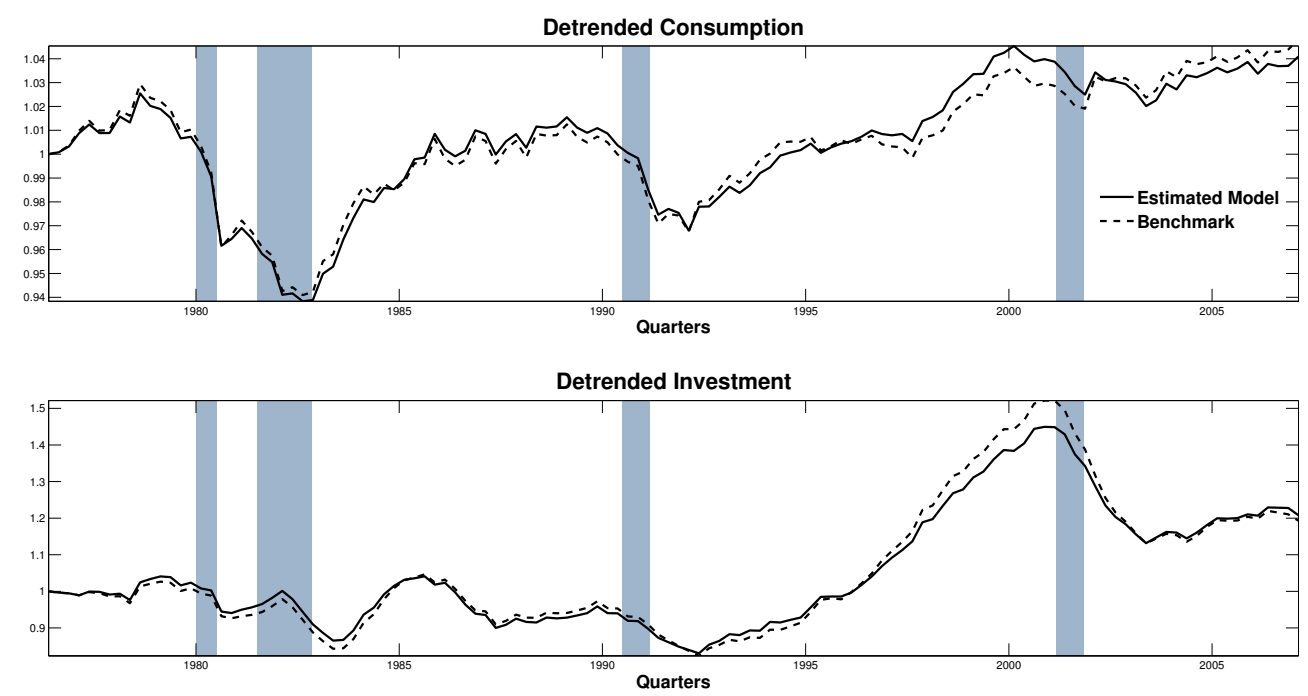

Notes. Shaded areas refer to NBER Recessions.

\subsection{Short-run Spillovers}

As shown in Section 4, exogenous shifts in advertising productivity are transmitted to the economy through adjustments in advertising spending and, therefore, drive the direct effects of advertising fluctuations on the other macro aggregates. To assess the quantitative importance of these effects at business cycle frequencies, panel A.1 of Table 5 reports the asymptotic variance decomposition in the estimated model. The results show that advertising-specific shocks $\left(\epsilon_{t}^{z}\right)$ contribute noticeably to the fluctuations in consumption, investment and markup accounting for $16.9 \%, 12.1 \%$ and $90 \%$ of their volatility, respectively. By contrast, the contribution to the volatility of total hours worked appears small $(4.12 \%)$, and the contribution to the volatility of GDP is almost null $(0.15 \%)$. The results in panel A.2 highlight that all of these effects vanish when the market-enhancing property is switched off $(\gamma=1)$, thereby showing that the labour reallocation effect alone has a negligible impact on macro aggregates. This finding confirms the long-run analysis on the importance of market-enhancing advertising, highlighting that the mechanisms driven by this property are also crucial for affecting the aggregate dynamics.

To quantify the overall spillovers resulting from the market-enhancing effect, we compute in-sample estimates of the historical role played by advertising in shaping U.S. aggregate dynamics. To this end, Figure 5 presents predicted consumption and investment (continuous lines) along with their counterparts implied by the benchmark model without advertising (dashed lines), whereas panel B of Table 5 (first row) reports the in-sample variance of selected endogenous variables in percentage deviations from their benchmark counterparts. ${ }^{5}$

\footnotetext{
${ }^{5}$ The reported results are obtained by setting the parameters to their posterior mean values and using the resulting smoothed estimates of the shocks to simulate both the baseline and benchmark models. To facilitate comparisons, the series reported in Figure 5 are normalized to equal 1 in the initial quarter. Predictions for the benchmark model without advertising are obtained from the baseline model by setting
}

This article is protected by copyright. All rights reserved. 
Figure 6: IRF of Consumption to Investment-Specific and Government Shocks
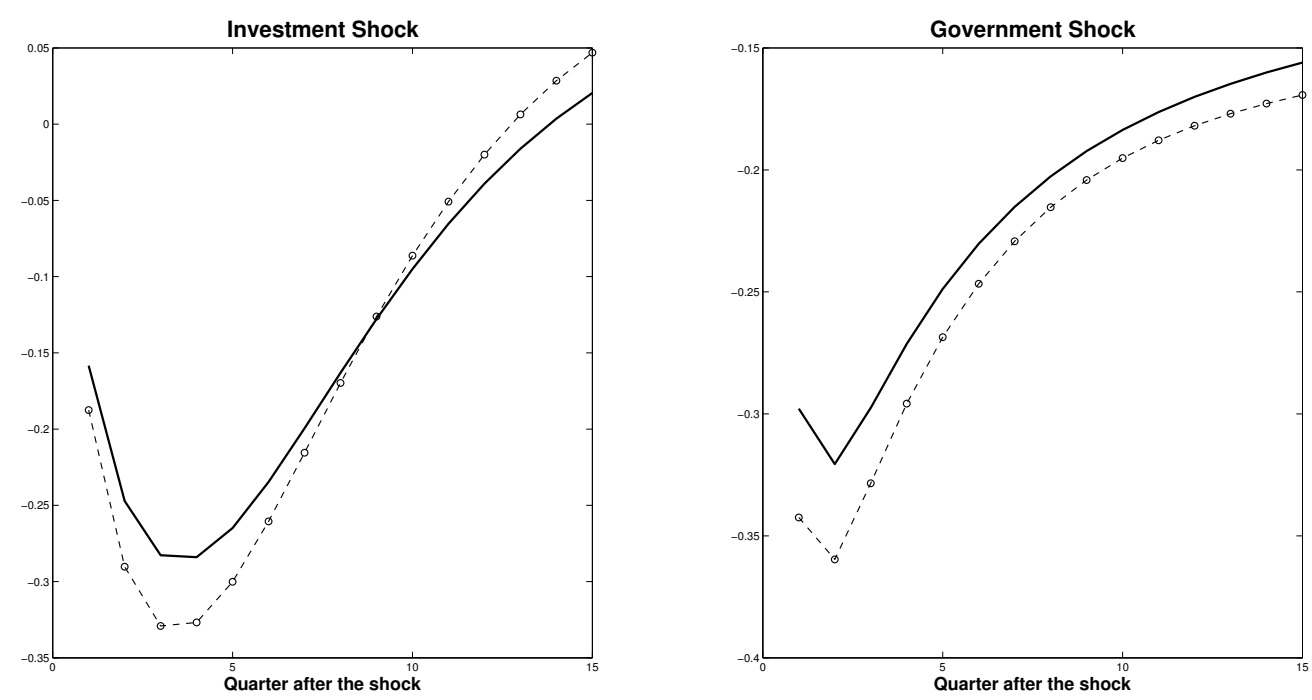

Estimated model

- - ๑- - Benchmark

Notes. The IRF in the estimated model are computed by setting all parameters to their posterior mean values. The IRF in the benchmark model without advertising are computed by setting $\theta=0$ while holding all the remaining parameters at their posterior mean values.

These statistics provide a comprehensive assessment of the short-run spillovers because, in addition to the direct effects driven by advertising-specific shocks, they also capture the indirect effects due to the impact of advertising on the transmission mechanisms of the other shocks. As Figure 5 illustrates, fluctuations in consumption are generally amplified by advertising. Quantitatively, the model predicts an average elasticity of aggregate consumption to the goodwill stock of $10 \%$ (i.e., $\eta_{c, f}(t)$ in equation 6 ), which results in a $22.5 \%$ increase in consumption volatility. Investment shows the opposite pattern, with in-sample volatility diminishing by $13.4 \%$ as result of the intertemporal effect of advertising. Regarding the remaining macro aggregates, we find that the presence of advertising significantly affects fluctuations of hours worked and GDP, increasing their volatilities by $15.8 \%$ and $12.9 \%$, respectively.

To establish in greater detail whether the positive relationship between advertising and consumption is determined by the direct or the indirect effects, in Table 5 (panel B, second row), we report the historical contribution of advertising to the volatility of the main aggregates recomputed by shutting down advertising-specific shocks. In this experiment, shock types are the same across the baseline and benchmark economy, and therefore, any difference in the volatility of the endogenous variables can be attributed to the indirect effects of advertising. The reported results show that in the absence of advertising-specific shocks, consumption volatility decreases with advertising, highlighting that (i) the direct effects are crucial for a positive advertising-consumption relationship in the short run and that (ii) the enhancing effect of advertising on the propensity to consume works as a dampening mechanism of any shock that crowds out consumption. This last result can be observed in Figure 6 , which shows that after a government or investment shock, consumption is less responsive

parameter $\theta=0$, whereas all of the other parameters are kept fixed at their posterior mean values.

This article is protected by copyright. All rights reserved. 
Table 6: Welfare Effects of Advertising
(A) Steady state
(B) Transitional dynamics
Median 90\% interval Median
$90 \%$ interval

\section{Welfare gains}

$\tau_{0}$ (percentages) $\quad-5.32 \quad[-0.69-16.2] \mid-7.61$

$\tau_{z}$ (percentages) $\quad-1.22 \quad\left[\begin{array}{lll}-0.16 & 3.59\end{array}\right]-2.80$

$[-21.2-3.55]$

$\left[\begin{array}{ll}-5.51 & 0.211\end{array}\right]$

\section{Advertising vs perfect competition}

$\left.\begin{array}{lll|l}H(Z) / H_{e} & 1.07 & {[1.01} & 1.17\end{array}\right]$ -

Notes. To account for parameter uncertainty, we construct a random section of 50,000 draws from the posterior distribution and compute the welfare effects in steady state (panel A) and along the transition path (panel B) for each draw. Summary statistics are then computed by pooling all the simulations. For each draw, the equilibrium allocations with the banning policy are computed from the estimated model by setting $\theta=0$. Equilibrium allocations with perfectly competitive products markets $\left(C_{e}\right.$ and $\left.H_{e}\right)$ are determined from the benchmark model without advertising $(\theta=0)$ by setting the average markup equal to 1 .

in the model with advertising, thus explaining why overall consumption volatility decreases when the advertising-specific shocks are shut down.

\subsection{Welfare Analysis}

What remains unclear from the previous analysis is whether advertising is beneficial for households. Advertising reduces welfare by inducing a higher markup that exacerbates the distortions of monopolistic competition, but it may also improve welfare by fostering consumption and hours worked, which potentially bring the economy closer to the competitive equilibrium. To assess the overall effect of advertising, in this section, we use the estimated model to perform a proper welfare analysis. In the presence of persuasive advertising, however, the welfare analysis is complicated because advertising changes consumers' tastes. Therefore, it is not obvious which reference welfare criterion should be used given that there are at least two natural yardsticks: the pre-advertising and post-advertising preference relations. ${ }^{6}$ To address this issue, we follow Bisin and Benhabib (2010) by relying on a welfare criterion that considers both preferences. Formally, let $Z$ and $U(C(Z), H(Z), Z)$ denote the equilibrium level of aggregate advertising and the inter-temporal utility function, respectively, associated with the allocation $\{C(Z), H(Z)\} \in R_{+}^{\infty}$. Then, a welfare criterion can be defined as follows.

Definition 1. The household is better off in the presence of advertising if and only if welfare increases with respect to post-advertising preferences,

$$
U(C(Z), H(Z), Z) \geq U(C(0), H(0), Z)
$$

${ }^{6}$ The issue is rather controversial in the literature. See Dixit and Norman (1978) and Bisin and Benhabib (2010) for a detailed discussion of this topic.

This article is protected by copyright. All rights reserved. 
Figure 7: Transitional Dynamics

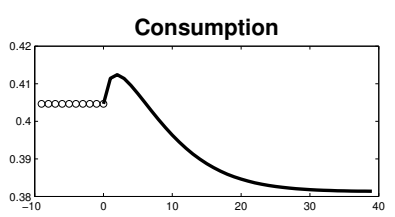

GDP
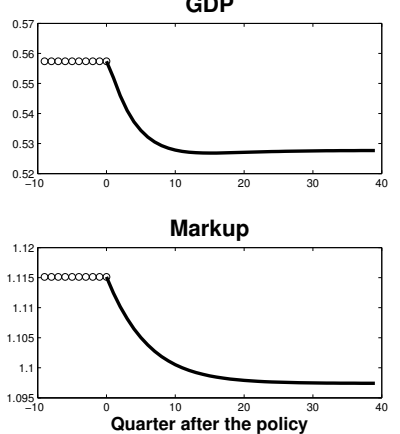

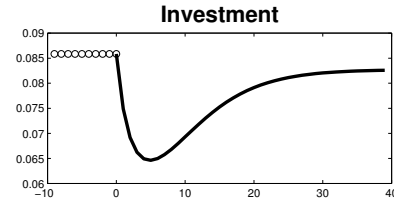

Goodwill
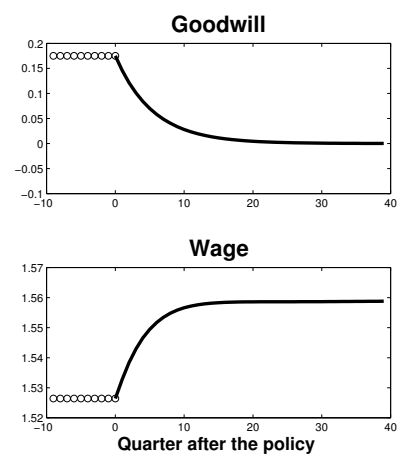

Hours

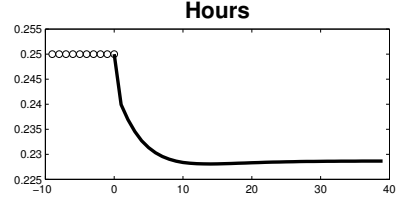

Advertising-related labor

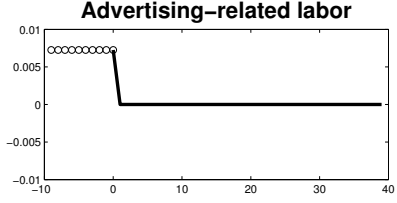

Capital Rental Rate

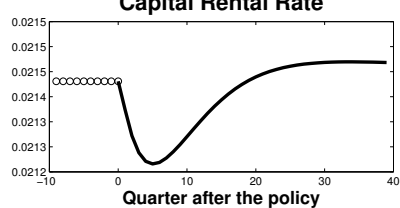

Notes. Initial dynamics of selected endogenous variables after a policy that bans advertising at time 0 . Parameters are set to their posterior mean values.

and it also increases with respect to pre-advertising preferences,

$$
U(C(Z), H(Z), 0) \geq U(C(0), H(0), 0)
$$

with at least one inequality holding strictly.

Definition 1 states that the consumer is better off with advertising $(Z>0)$ if and only if he prefers the allocation $\{C(Z), H(Z)\}$ to the allocation $\{C(0), H(0)\}$, regardless of which welfare yardstick is used. In particular, we compute the welfare gains of advertising as the percentage decrease in consumption that is required to make the household as well off as under a policy that totally bans advertising, i.e.,

$$
U\left(\left(1-\tau_{s}\right) C(Z), H(Z), s\right)=U(C(0), H(0), s) \text { with } s=\{0, z\},
$$

where $\tau_{z}$ and $\tau_{0}$ denote the welfare gains associated with pre-advertising and post-advertising preferences, respectively. Hence, Definition 1 holds when both $\tau_{0} \geq 0$ and $\tau_{z} \geq 0$ with at least one inequality holding strictly, whereas $\tau_{s}<0$ entails a welfare cost of advertising. The results are reported in panels $\mathrm{A}$ and $\mathrm{B}$ of Table 6 . The first panel refers to the direct comparison of welfare between the pre- and post-policy steady states. The second panel reports the results when computing the welfare costs along the entire transition from one steady state to the other. Regarding the long-run equilibrium, we find that advertising is unambiguously detrimental to welfare because the household is worse off according to both ex ante and ex post preferences. For instance, with ex ante preferences, a compensation in consumption of $5.32 \%$ is required to make households indifferent between the pre- and post-policy allocations. The origin of this result can be traced back to the overworking effect induced by advertising, which is apparent when comparing the steady state of the estimated model with that of a perfectly competitive economy. As reported in panel A, advertising 
pushes households to work $7 \%$ more hours, while they enjoy only $2 \%$ more consumption with respect to the efficient allocations, thus explaining the observed welfare losses. Panel $B$ shows that this welfare-detrimental effect is even stronger when the transitional dynamics are taken into account, in which case welfare costs increase to $7.61 \%$. Figure 7 illustrates that this amplification effect is due to the hump-shaped dynamics of consumption, which implies that for several quarters after the banning of advertising, households work less and consume more with respect to the pre-policy steady state.

\section{Conclusions}

This paper assesses the role of marketing practices in stimulating aggregate consumption and economic activity. By estimating a variant of the neoclassical growth model that has been developed to account for firms' spending on advertising, we show that in the U.S., advertising has a relevant long-run effect on consumption and working activities. The underlying mechanism operates through a work and spend channel: in the presence of advertising, people work more to afford greater purchases of goods, and the perceived need for higher consumption results from the advertising signals to which consumers are exposed. Because of this effect, advertising enhances the production of output, eventually increasing consumption and investment. In the short run, the effect of the work and spend channel is offset by an intertemporal substitution mechanism that is absent in the long run. In reaction to increases in firms' spending on advertising, households substitute current consumption for savings, and the resulting reduction in aggregate investment partially offsets the increase in aggregate consumption, thereby softening the impact of advertising on output and hours worked. Overall, we show that advertising affects the business cycle primarily through the dynamics of consumption, investment and markup.

Benedetto Molinari, University of Malaga and RCEA

Francesco Turino, Universidad de Alicante

\section{References}

Ashley, R., Granger, C.W.J. and Schmalensee, R. (1980). 'Advertising and aggregate consumption: An analysis of causality', Econometrica, vol. 48(5), pp. 1149-67.

Bagwell, K. (2007). The Economic Analysis of Advertising, vol. 3 of Handbook of Industrial Organization, chap. 28, Elsevier, pp. 1701-1844.

Baker, M.J. and George, L.M. (2010). 'The role of television in household debt: Evidence from the 1950's', The B.E. Journal of Economic Analysis \& Policy, vol. 10(1).

Bisin, A. and Benhabib, J. (2010). Social Construction of Preferences: Advertising, vol. 1A of Handbook of Social Economics, Elsevier, pp. 201-220.

Chowdhury, A.R. (1994). 'Advertising expenditures and the macroeconomy: Some new evidence', International Journal of Advertising, vol. 13(1), pp. 1-14.

This article is protected by copyright. All rights reserved. 
Dixit, A. and Norman, V. (1978). 'Advertising and welfare', Bell Journal of Economics, vol. 9(1), pp. 1-17.

Dorfman, R. and Steiner, P.O. (1954). 'Optimal Advertising and Optimal Quality', American Economic Review, vol. 44(5), pp. 826-836.

Fraser, S. and Paton, D. (2003). 'Does advertising increase labour supply? time series evidence from the uk', Applied Economics, vol. 35(11), pp. 1357-1368.

Galbraith, J.K. (1958). The Affluent Society, Houghton Mifflin Company.

Grossmann, V. (2008). 'Advertising, in-house r\&d, and growth', Oxford Economic Papers, vol. 60(1), pp. 168-191.

Hall, R.E. (2008). 'General Equilibrium with Customer Relationships: A Dynamic Analysis of Rent-Seeking', .

Iacoviello, M. and Neri, S. (2010). 'Housing market spillovers: Evidence from an estimated dsge model', American Economic Journal: Macroeconomics, vol. 2(2), pp. 125-64, doi: 10.1257/mac.2.2.125.

Jung, C. and Seldon, B.J. (1995). 'The macroeconomic relationship between advertising and consumption', Southern Economic Journal, vol. 61(3), pp. 577-587.

Kamakura, W.A. and Russell, G.J. (1993). 'Measuring brand value with scanner data', International Journal of Research in Marketing, vol. 10(1), pp. 9-22.

Karray, S. and Martn-Herrn, G. (2009). 'A dynamic model for advertising and pricing competition between national and store brands', European Journal of Operational Research, vol. 193(2), pp. 451-467.

Leone, R.P. (1995). 'Generalizing what is known about temporal aggregation and advertising carryover', Marketing Science, vol. 14(3), pp. pp. G141-G150.

Nerlove, M. and Arrow, K.J. (1962). 'Optimal advertising policy under dynamic conditions', Economica, vol. 29(114), pp. 129-142.

Ravn, M., Schmitt-Grohe, S. and Uribe, M. (2006). 'Deep habits', Review of Economic Studies, vol. 73(1), pp. 195-218.

Roberts, M.J. and Samuelson, L. (1988). 'An empirical analysis of dynamic, nonprice competition in an oligopolistic industry', RAND Journal of Economics, vol. 19(2), pp. 200-220.

Seldom, B.J. and Jung, C. (1995). 'The length of the effect of aggregate advertising on aggregate consumption', Economics Letters, vol. 48(2), pp. 207-211.

Smets, F. and Wouters, R. (2007). 'Shocks and frictions in us business cycles: A bayesian dsge approach', American Economic Review, vol. 97(3), pp. 586-606.

This article is protected by copyright. All rights reserved. 
Taylor, L.D. and Weiserbs, D. (1972). 'Advertising and the aggregate consumption function', American Economic Review, vol. 62(4), pp. 642-55.

Vakratsas, D. and Ambler, T. (1999). 'How Advertising Works: What Do We Really Know?', The Journal of Marketing, vol. 63(1), pp. 26-43.

\section{Appendix A. Data}

\begin{tabular}{|c|c|c|c|}
\hline \multicolumn{4}{|c|}{ Data on Aggregate Advertising } \\
\hline Robert J. Coen & All Media & Annual & $1948-2007$ \\
\hline AD $\$$ Summary journal & All Media & Quarterly & 1976.I-2006.IV \\
\hline Newspaper Association of America & Newspapers & Quarterly & 1976.I-2006.IV \\
\hline
\end{tabular}

\section{Business Cycle Indicators}

Macroeconomic Variable Code Freq. Sample

\begin{tabular}{lcll} 
Real GDP & GDPC96 & Quarterly & 1976.I-2006.IV \\
Real Export & EXPGSC96 & Quarterly & 1976.I-2006.IV \\
Real Import & IMPGSC96 & Quarterly & 1976.I-2006.IV \\
Real Personal Consumption Exp. & PCECC96 & Quarterly & 1976.I-2006.IV \\
Real PCE: Durable Goods & PCDGCC96 & Quarterly & 1976.I-2006.IV \\
Real PCE: Nondurable Goods & PCNDGC96 & Quarterly & 1976.I-2006.IV \\
Real Private Fixed Investment & FPIC96 & Quarterly & 1976.I-2006.IV \\
GDP Implicit Price Deflator & GDPDEF & Quarterly & 1976.I-2006.IV \\
Civ. Non-Instit. Population & CNP160V & Quarterly & 1976.I-2006.IV \\
Civ. Employment-Pop. Ratio & EMRATIO & Quarterly & 1976.I-2006.IV \\
Average weekly hours of employees & CES05007* & Quarterly & 1976.I-2006.IV \\
\hline \hline
\end{tabular}

All Media refers to: Magazines, Sunday Magazines, Newspapers, Network Televisions, Spot/Local Televisions, Syndicated Televisions, Cable Televisions, Spot/Local Radio, Syndicated Radio, Outdoor.

Data sources. Coen: Douglas Galbi's blog (purplemotes.net/2009/05/10/robert-j-coen-advertising-datahero); AD\$Summary: Library of the Johnson Graduate School of Management (Cornell University); NAA: Newspaper Association of America media center (www.naa.org); Business Cycle Indicators. FRED II: Federal Reserve Bank of St. Louis (research.stlouisfed.org/fred2); *CES: U.S. Bureau of Labor Statistics (www.bls.gov/ces).

This article is protected by copyright. All rights reserved. 